\section{Train in a new approach to aesthetic teeth straightening}

Align Technology has called in Drs Raman Aulakh and Barry Buckley - who are among the most respected names in Invisalign training - to help general dentists fresh to the Invisalign system get up and running with a new approach to aesthetic teeth straightening.

From October, Aligner Consulting will be holding a series of countrywide day-long courses for GDPs, with a parallel session for practice managers, in association with Laura Horton of Horton Consulting.

Those who join their coaching programme will benefit from a blended learning approach to Invisalign accreditation which combines lectures with hands-on training. The programme has been specifically created to help GDPs develop new skills which will help them extend their practices to treat patients with the much-requested Invisalign system. The course is also designed to provide their practice staff with the impetus to promote the treatment with fluency and confidence.

The autumn season kicks off in Bristol on 8 October and also visits Newcastle, Manchester and runs up until 28 November in London. An extensive 36 -city venue programme is being created for 2017. Because of its interactive nature and hands-on element, course places are strictly limited to 40 dentists and 40 accompanying practice managers. The course for GDP and practice manager costs $£ 595$ (with no added VAT, but no discount for one person) which includes ongoing mentoring, forum access and support. Dentists keen to secure a place at their first choice venue and date are encouraged to register online at go.alignerconsulting.com as early as possible.

\section{Recalls and reminders... without the huge expense?}

Computerised dental practices have become common place over the last 15 years. The advantages of moving away from the racks of filing cabinets full of paper files are obvious, yet despite this there is still some nervousness amongst a small number of practices with a well-run paper based operation to change. Some of this is understandable... after all, why change a system that works?

iSmile is available in a Lite version, with no upfront cost. Released in 2013 it has helped practices take the plunge from a paper based operation to having patient records, FP17 forms and appointment diaries digitised. This gives the practice a data backbone to work up from, recording important information which can then be used to make decisions in order to grow the business. Users have the option to upgrade to the full clinical version of iSmile too, reducing paperwork further by introducing the clinical charting module as well as other features such as the online patient portal.

The data, processes and workflow present in practice management systems is the best resource for marketing too. Using a system that automates processes and relieves pressure from practice managers and owners can result in double digit growth in revenues and significantly improve patient perceptions with a more 'connected' experience in the digital age.

For more information call 0845468 1287, email info@ismiledental.co.uk or visit www. ismiledental.co.uk

Visit iSmile on Stand H30 at the BDIA Dental Showcase, ExCel London.

\section{iSmile DENTAL SOFTWARE \\ HEADACHE FREE SOFTWARE \& SUPPORT}

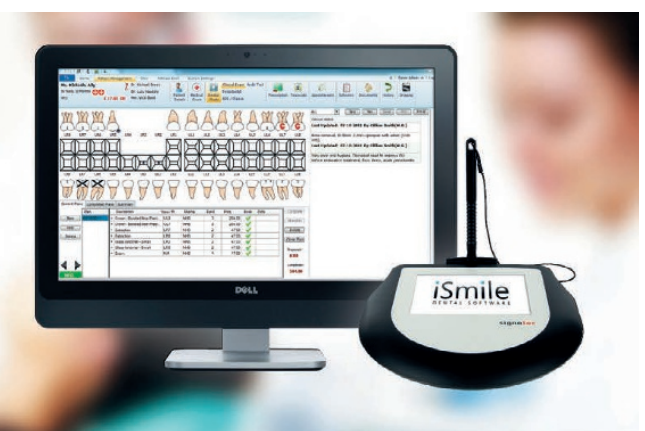

\section{Bright smiles, bright futures}

How do you interact with your neighbourhood beyond your practice boundaries and influence the local population you serve? By participating in the Colgate Bright Smiles, Bright Futures 2016 CPD programme, focused on children and community engagement, your practice can get involved and influence the oral health of the local population through providing evidencebased advice and guidance. Engagement can be via a range of settings such as primary schools, nursery, children's clubs (brownies, cubs, local football team etc) or any other community group involving children.

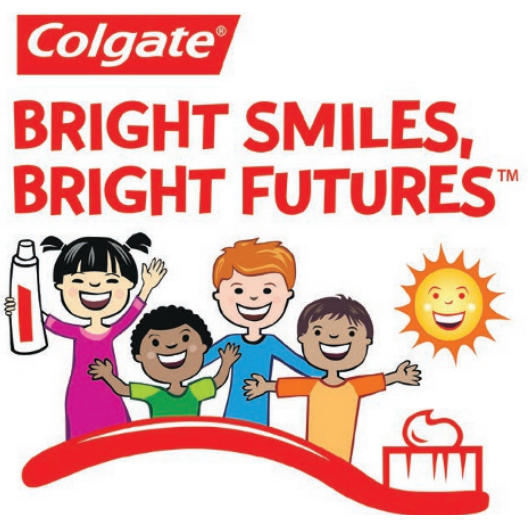

Having the opportunity for your practice to participate in a community based activity is also a great way of promoting your practice. Additionally, community engagement activities also provide leadership opportunities for you and your team members to develop additional skills.

To download this year's CPD programme visit www.colgateprofessional.co.uk. Then you just complete the online feedback and reflection form and upload any supporting materials you would like to share along with any pictures you take during your activity. On completion and submission of your CPD feedback and reflection form you will receive a certificate for 3 hours CPD. In December 2016, the best practice entry as judged by a panel from the BDA and British Association for the Study of Community Dentistry (BASCD) will receive a Community Engagement Award presented during the BDA British Dental Conference 2017. 